\title{
Aortocaval Fistula in Rat: A Unique Model of Volume-Overload Congestive Heart Failure and Cardiac Hypertrophy
}

\author{
Zaid Abassi, ${ }^{1,2}$ Ilia Goltsman, ${ }^{1}$ Tony Karram, ${ }^{3}$ Joseph Winaver, ${ }^{1}$ and Aaron Hoffman ${ }^{3}$ \\ ${ }^{1}$ Department of Physiology and Biophysics, Rappaport Faculty of Medicine, Technion, IIT, P.O. Box 9649, Haifa 31096, Israel \\ ${ }^{2}$ Research Unit, Rambam Medical Center, Haifa 31096, Israel \\ ${ }^{3}$ Department of Vascular Surgery, Rambam Medical Center, Haifa 31096, Israel
}

Correspondence should be addressed to Zaid Abassi, abassi@tx.technion.ac.il

Received 5 October 2010; Accepted 9 December 2010

Academic Editor: Oreste Gualillo

Copyright (C) 2011 Zaid Abassi et al. This is an open access article distributed under the Creative Commons Attribution License, which permits unrestricted use, distribution, and reproduction in any medium, provided the original work is properly cited.

\begin{abstract}
Despite continuous progress in our understanding of the pathogenesis of congestive heart failure (CHF) and its management, mortality remains high. Therefore, development of reliable experimental models of CHF and cardiac hypertrophy is essential to better understand disease progression and allow new therapy developement. The aortocaval fistula (ACF) model, first described in dogs almost a century ago, has been adopted in rodents by several groups including ours. Although considered to be a model of high-output heart failure, its long-term renal and cardiac manifestations are similar to those seen in patients with low-output CHF. These include $\mathrm{Na}^{+}$-retention, cardiac hypertrophy and increased activity of both vasoconstrictor/antinatriureticneurohormonal systems and compensatory vasodilating/natriuretic systems. Previous data from our group and others suggest that progression of cardiorenal pathophysiology in this model is largely determined by balance between opposing hormonal forces, as reflected in states of CHF decompensation that are characterized by overactivation of vasoconstrictive/ $\mathrm{Na}^{+}$-retaining systems. Thus, ACF serves as a simple, cheap, and reproducible platform to investigate the pathogenesis of $\mathrm{CHF}$ and to examine efficacy of new therapeutic approaches. Hereby, we will focus on the neurohormonal, renal, and cardiac manifestations of the ACF model in rats, with special emphasis on our own experience.
\end{abstract}

\section{Introduction}

Congestive Heart failure (CHF) is a clinical syndrome characterized by cardiac dysfunction and myocardial structural abnormality (e.g., hypertrophy and dilated cardiomyopathy) resulting in inability of the heart to eject sufficient blood to the metabolizing tissues. CHF is a leading cause of morbidity and mortality, posing a major health and economic burden in the Western world [1]. Nearly 5 million Americans and 6.5 million Europeans suffer from heart failure, which accounts for $20 \%$ of all hospitalizations among patients over the age of 65 , and its related complications result in one million admissions with an annual mortality rate of $8 \%-10 \%$ [2]. Moreover, CHF has enormous economic impact because of the high costs of the treatment, frequent hospitalizations, and poor quality of life. Therefore, understanding the basic mechanisms leading to the development of CHF and its complications, as well as the discovery of innovative adequate treatment for CHF are crucial in order to improve the outcome of this devastating disease. The ideal model should be able to reproduce each of the aspects of the progression of clinical CHF. However, none of the models available is able to entirely reproduce CHF. While some models reproduce neuroendocrine changes, others better reproduce the remodeling that occurs during chronic heart failure. Nevertheless, the progress that has been made so far and the expected future achievements in this field would not have been possible without the continuous development of experimental models of heart failure and hypertrophy in small and large animals, where each one has its unique advantages and limitations. Among these models, one can mention coronary ligation, aortic banding, salt-sensitive and spontaneous hypertension, toxic cardiomyopathy, rapid pacing, and aortocaval fistula (ACF) (for more details see [3]). The latter was induced for the first time in dogs in 1923, and adopted to rats in 1973 by Stumpe et al. $[4,5]$. 
The transition from large animals to rodents is of special value since powerful genomic tools such as transgenic and knockout technologies are now available for the rat in addition to mice.

\section{The Experimental Model of Aortocaval Fistula: Methodological Aspects}

Over the last 2 decades our group has been studying the pathophysiology of heart failure using rats with ACF as an experimental model of volume-overload CHF [6-13]. Heart failure is induced in this model by surgical creation of an arteriovenous (AV) fistula between the abdominal aorta and inferior vena cava, distal to the origin of the renal arteries, as described by Stumpe et al. [4]. In short, under binocular magnification the common wall between the inferior vena cava and the abdominal aorta is grasped through a longitudinal incision made in the inferior vena cava, and a fistula is created between the 2 vessels (side to side, $1.0-1.2 \mathrm{~mm}$ in length). The opening in the vena cava is then closed by a continuous suture (see Figure 1). A similar procedure was adopted to produce severe cardiac hypertrophy in the mouse [14]. Other investigators have used a simplified and quicker technique by insertion of a 18 gauge needle through the abdominal aorta and creating a fistula in the common wall of the vessels, followed by closure of the puncture in the aorta by cyanoacrylate glue $[15,16]$.

A unique property of our rats with ACF, not reported in other experimental models of CHF, is the ability to divide these animals into 2 subgroups based on the pattern of their daily sodium excretion after creating the fistula [7]. While both subgroups show avid renal retention of sodium and water in the early phase after surgery, the majority of ACF rats $(\sim 80 \%)$ can increase their urinary sodium excretion to baseline levels and return to balance after 7-10 days. The other subgroup continues to retain salt and water and dies from symptoms of pulmonary edema and ascites formation, similar to patients with severe clinical CHF. We termed these subgroups as "compensated" and "decompensated" $\mathrm{CHF}$ rats, respectively, which allowed us to characterize these subgroups and study the factors that may contribute to deterioration from compensated to a decompensated state (Figure 2 and Table 1) [7, 10].

It should be emphasized that the AV fistula model has been used also in other species, primarily dogs, to study the pathophysiology of CHF [18-24]. Also, the circulatory and renal consequences in patients with posttraumatic AV fistula were reported in classic studies in the past and served in many respects as a drive for the investigations in the animal models [25-27]. The current review summarizes the neurohormonal, renal and cardiac characteristics of rats with ACF, with special focus on our own studies.

\section{Neurohormonal Alterations}

3.1. Vasoconstrictor/Antinatriuretic Systems. Creation of ACF results in an immediate and sustained decrease in mean arterial pressure together with a substantial increase in venous blood flow to the right heart. These hemodynamic changes result in compensatory activation of several neurohormonal systems as well as in adaptive structural alterations in myocardium and vascular system, as shown previously by other investigators [19, 28, 29]. Among the neurohumoral systems that are activated in response to ACF creation one can find the classical vasoconstrictor/antinatriuretic systems including the renin-angiotensin-aldosterone axis (RAAS), the sympathetic nervous system (SNS), the antidiuretic hormone $(\mathrm{ADH})$ and the endothelin-1 (ET-1), acting via the $\mathrm{ET}_{\mathrm{A}}$ receptor. Activation of the classic vasoconstrictor systems is thought to be mediated in part by the sustained decrease in MAP that occurs following the placement of the fistula, sensed by the baroreceptors in the arterial circulation. Both the increased activity of the SNS with high circulating levels of catecholamines, as well as the increase in the nonosmotic $\mathrm{ADH}$ release may be mediated by a similar mechanism. In addition, renal hypoperfusion may serve as a potent stimulus for the activation of the RAAS.

The RAAS plays a fundamental role in the pathogenesis of the cardiovascular and renal manifestations in experimental models of CHF, in particular in rat and canine models of ACF [7, 30-33]. Although initially activated to support systemic BP by direct systemic vasoconstriction, by facilitating the central and peripheral effects of the sympathetic nervous system and by promoting renal sodium retention, many of the biological activities of the system turn to be "maladaptive" during the progression of the disease, and contribute significantly to the deterioration, both in clinical and in experimental CHF models [34]. In particular, recent studies implicated both angiotensin II (ang II) and aldosterone as potential mediators of the deterioration in cardiac and renal function in severe $\mathrm{CHF}[9,35]$.

The RAAS is activated in the early phases after creation of the AV fistula and plays a major role in the induction of cardiac hypertrophy and changes in renal function in this model $[12,31,32,36]$. In particular, we have shown that the main difference between the "compensated" and "decompensated" subgroups of rats with ACF relates to the degree of activation of the RAAS in these subgroups, as evaluated by their plasma renin activity (PRA) [7]. Increased activity of the RAAS is thought to act by "blocking" the natriuretic/vasodilatory effect of ANP in the kidney, thereby leading to avid renal sodium and water retention and edema formation $[13,33]$. In addition, increased activity of the RAAS may contribute to the impairment of endothelialdependent renal vasodilatation and the development of "endothelial dysfunction" in rats with ACF [11]. In view of the central role of the RAAS in the induction of CHF in animals with ACF it is not surprising that pharmacological blockade of this neurohumoral axis either by ACE inhibitors or angiotensin receptor blockers (ARBs) provides beneficial effects in this experimental model of CHF [7, 32, 33, 37, 38].

The SNS is another vasoconstrictor/antinatriuretic system that is activated in early in the course of CHF [39]. While the role of the SNS in mediating systemic and renal vasoconstriction and sodium retention is well established in other experimental models of $\mathrm{CHF}$, the contribution of increased sympathetic activity in animals with ACF has not 
TABLE 1: Neurohumoral, hemodynamic and renal characteristics of sham operated rats and rats with compensated and decompensated CHF (see $[7,8,10,12,17])$.

\begin{tabular}{|c|c|c|c|c|}
\hline & Parameter & Sham & CHF-compensated & CHF-decompensated \\
\hline \multirow{6}{*}{ Neurohumoral } & PRA (ng Ang/ml/min) & $14.0 \pm 3.0$ & $31.2 \pm 20.2$ & $47.0 \pm 14.0$ \\
\hline & Aldosterone (pg/ml) & $243.9 \pm 72.1$ & $399.1 \pm 57.9^{a}$ & $1266.4 \pm 252.4^{\mathrm{a}, \mathrm{b}}$ \\
\hline & $\operatorname{AVP}(\mathrm{pg} / \mathrm{ml})$ & $14.2 \pm 3.6$ & $36.1 \pm 13.8^{\mathrm{a}}$ & $37.7 \pm 9.6^{\mathrm{a}}$ \\
\hline & Epinephrine (pg/ml) & $667 \pm 175.9$ & $449.0 \pm 339.0$ & $2049.8 \pm 496.9^{\mathrm{a}, \mathrm{b}}$ \\
\hline & Norepinephrine $(\mathrm{pg} / \mathrm{ml})$ & $184.2 \pm 40.5$ & $481.0 \pm 20.0^{\mathrm{a}}$ & $1112.6 \pm 293.2^{\mathrm{a}, \mathrm{b}}$ \\
\hline & $\operatorname{ANP}(\mathrm{pg} / \mathrm{ml})$ & $94 \pm 12$ & $382 \pm 115^{\mathrm{a}}$ & $389 \pm 135^{\mathrm{a}}$ \\
\hline \multirow{3}{*}{ Hemodynamic } & CVP (mmHg) & $4.5 \pm 1.6$ & $16.4 \pm 3.9^{\mathrm{a}}$ & \\
\hline & MAP (mmHg) & $151 \pm 4$ & $125 \pm 5^{\mathrm{a}}$ & $103 \pm 5^{\mathrm{a}, \mathrm{b}}$ \\
\hline & $\mathrm{CO}(\mathrm{ml} / \mathrm{min})$ & $72.6 \pm 5.9$ & $114.9 \pm 15.5^{\mathrm{a}}$ & \\
\hline \multirow{3}{*}{ Renal } & $\operatorname{GFR}(\mathrm{ml} / \mathrm{min})$ & $1.96 \pm 0.16$ & $1.57 \pm 0.21^{\mathrm{a}}$ & $0.89 \pm 0.12^{\mathrm{a}, \mathrm{b}}$ \\
\hline & $\mathrm{RBF}(\mathrm{ml} / \mathrm{min})$ & $6.01 \pm 0.29$ & $2.81 \pm 0.14^{\mathrm{a}}$ & $2.17 \pm 0.12^{\mathrm{a}}$ \\
\hline & $\mathrm{UNaV}(\mathrm{mEq} / \mathrm{min})$ & $1.69 \pm 0.49$ & $0.45 \pm 0.08^{\mathrm{a}}$ & $0.16 \pm 0.11^{\mathrm{a}, \mathrm{b}}$ \\
\hline
\end{tabular}

PRA: Plasma renin activity, AVP: Arginine vasopressin, ANP: Atrial natriuretic peptide, CVP: Central venous pressure, MAP: Mean arterial pressure, CO: Cardiac output, GFR: Glomerular filtration rate, RBF: Renal Blood flow, $\mathrm{U}_{\mathrm{Na}} \mathrm{V}$ : Urinary sodium excretion.

${ }^{\mathrm{a}} P<.05$ versus sham operated rats, ${ }^{\mathrm{b}} P<.05$ versus compensated CHF. Values are means + SEM.

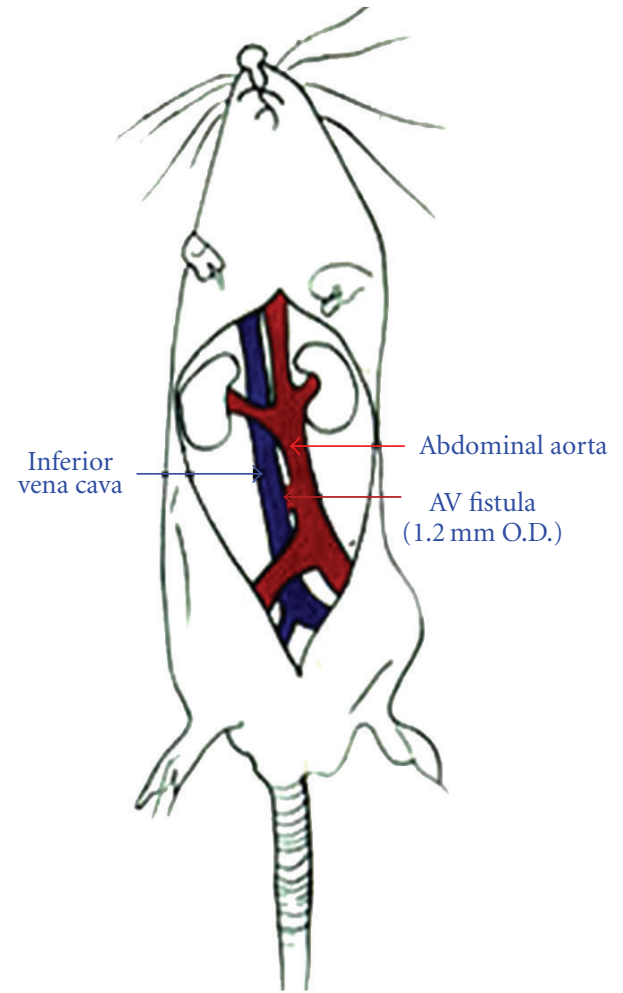

FIGURE 1: A schematic description of the creation of aortocaval fistula (ACF) in rats, an experimental model of volume-overload CHF.

been studied thoroughly. Earlier studies suggest that there is an attenuated response of aortic baroreceptor discharge in dogs with chronic volume overload due to ACF, and this abnormality may partially be responsible for the abnormal baroreflex in heart failure $[19,40]$. In other studies in dogs with ACF Villarreal et al. [24, 41] demonstrated that

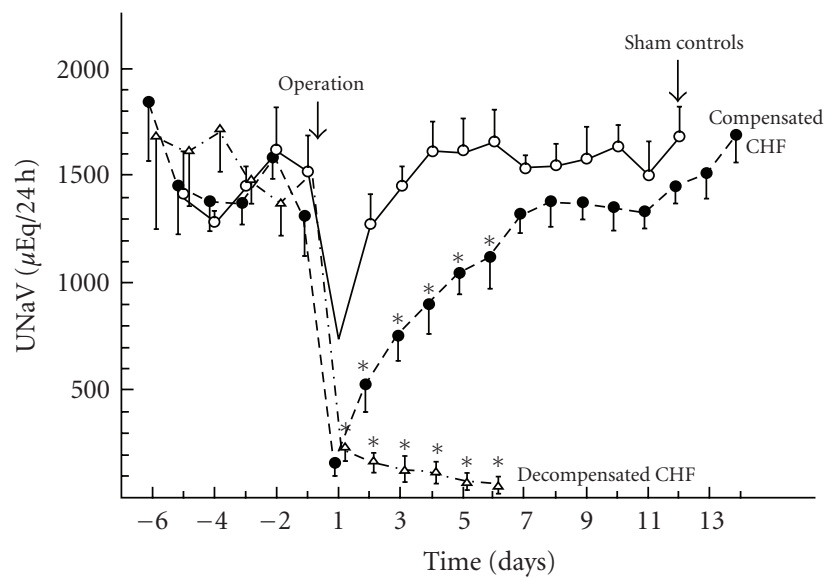

Figure 2: Daily urinary sodium excretion ( $\mathrm{UNaV}$ ) in rats with arteriovenous (AV) fistula and in sham controls. Notice 2 distinct patterns of sodium excretion in rats with AV fistula, compensated and decompensated that are statistically different $(P<.05)$ compared with sham controls. ${ }^{*} P<.05$ versus sham-operated rats.

renal denervation improved the natriuretic response to atrial natriuretic peptide and postprandial sodium excretion, suggesting that increased renal sympathetic activity contributes to salt retention in this canine model of CHF.

Antidiuretic Hormone (ADH) is synthesized in the brain and secreted from the posterior pituitary gland into the circulation in response to an increase in plasma osmolality (via osmoreceptor stimulation) or a decrease in effective circulating volume and blood pressure (via baroreceptors stimulation) [42]. ADH exerts its biological actions through $\mathrm{G}$-protein coupled receptors. Two of these receptors, $\mathrm{V}_{1 \mathrm{~A}}$ and $\mathrm{V}_{2}$, are abundantly expressed in the cardiovascular system and the kidney and mediate the two main biological actions of the hormone, namely, vasoconstriction and increased 
water reabsorption by the kidney [43]. ADH plasma levels are elevated in experimental $\mathrm{CHF}$, including rats with $\mathrm{ACF}$ [44]. Similarly, numerous studies have demonstrated that plasma levels of $\mathrm{ADH}$ are elevated in patients with $\mathrm{CHF}$ mostly in advanced CHF with hyponatremia, and also in asymptomatic patients with left ventricular dysfunction $[45,46]$. The mechanisms underlying the enhanced secretion of $\mathrm{ADH}$ in $\mathrm{CHF}$ are related to nonosmotic factors such as attenuated compliance of the left atrium, hypotension, and activation of the RAAS $[47,48]$. Since the main effect of $\mathrm{ADH}$ in $\mathrm{CHF}$ is the production of hyponatremia, it will be discussed in the section of renal manifestation $[47,49]$.

The endothelin system consists of 3 vasoactive peptides, namely, endothelin-1 (ET-1), endothelin 2 (ET-2), and endothelin 3 (ET-3). These peptides are synthesized and released mainly by endothelial cells and act in a paracrine/autocrine mode of action $[50,51]$. Endothelin-1, the main representative of the ET family, is the most potent vasoconstrictor known at present. The ETs bind to two distinct receptors designated ETA and ETB. Both receptors are expressed in a variety of tissues, including blood vessels, kidney, myocardium, lung, and brain [50-52]. The vasoconstrictor response to ET is induced by a ETA receptor mediated increase in cytosolic $\mathrm{Ca} 2+$. The endothelium-dependent relaxation is mediated by the ETB receptors via NO and PGs coupled mechanism. The kidney is both a source of ET production (mainly the inner medulla) and an important target organ of the peptide.

The pathophysiological role of ET- 1 in CHF is supported by two major lines of evidence: (1) Several studies have demonstrated that the ET system is activated in CHF [53-55]. (2) Some clinical and experimental studies have shown that ET-1 receptor antagonists modify this pathophysiologic process. The first line of evidence is based on the demonstration that plasma ET-1 levels and the concentrations of its precursor, Big ET-1, are elevated both in clinical $\mathrm{CHF}$ and experimental models of CHF, and correlate with hemodynamic severity and symptoms $[56,57]$. In rats with ACF, there was a prompt three-to-fourfold increase in ET1 mRNA in atria and a progressive five-to-sevenfold rise in ventricles during cardiac hypertrophy [58]. Cavero et al. [59] reported that plasma immunoreactive ET-1 levels are elevated 2- to 3-fold above normal in dogs with CHF induced by rapid ventricular pacing. Elevated circulating ET-1 levels have also been reported in patients with $\mathrm{CHF}$ [56].

3.2. Vasodilatory/Natriuretic Systems. Concomitantly with the stimulation of the vasoconstrictor neurohumoral systems, compensatory vasodilatory/natriuretic systems are also activated in rats with ACF, serving to counterbalance the actions of the opposing vasoconstrictor systems. Among these vasodilatory/natriuretic agents, those particularly studied in animals with AV fistula are the natriuretic peptides, primarily atrial natriuretic peptide (ANP), the nitric oxide (NO) system, and the vasodilatory prostaglanding $\mathrm{E}_{2}$ $\left(\mathrm{PGE}_{2}\right)$. In many respects, the cardiovascular and renal status in rats with ACF is determined by the balance between these opposing neurohumoral systems, as will be outlined in the following sections.
Atrial natriuretic peptide (ANP) and B-type natriuretic peptide (BNP) are circulating hormones of cardiac origin which play important roles in the compensation of congestive heart failure with their vasodilating, natriuretic, antiproliferative, and neurohumoral-modulating properties $[60,61]$. The natriuretic peptides and in particular ANP have been studied extensively in the ACF model of CHF $[6,7$, $23,33,62-64]$. This experimental model is characterized by a marked increase in right atrial pressure as a consequence of the diversion of a large proportion of the arterial blood flow to the venous circulation. Given that distention of atria is the most potent physiological stimulus for ANP release into the circulation, it is reasonable to assume that plasma levels of ANP are markedly elevated in this model. Indeed, we demonstrated that plasma levels of ANP were approximately 20 times higher compared with sham-operated controls. Plasma ANP increased already $24 \mathrm{hrs}$ after creation of the fistula and remained elevated for the entire first week of observation, to the same extent in both the "compensated" and the "decompensated" subgroups of rats with ACF [7]. In similarity with patients with heart failure, significant elevations in plasma ANP levels were reported by other investigators also in the canine model of ACF as well as in other experimental models of CHF [24, 33, 65-67]. The common finding of high circulating ANP levels in CHF appears to be at odds with the tendency to salt and water retention by kidney, a characteristic finding in patients and experimental models of $\mathrm{CHF}$ that might suggest that the natriuretic/diuretic effects of the peptide are attenuated in CHF. The mechanisms proposed to explain the phenomenon of "ANP resistance" in CHF include hemodynamic changes leading to a decrease in renal perfusion, activation of vasoconstrictor/antinatriuretic neurohumoral systems such as the RAAS and SNS, downregulation of ANP receptors, increased degradation of ANP or its 2nd messenger cGMP, and release of less active forms of ANP in CHF [13]. A consistent finding in our studies is the observation that removal of the influence of the RAAS, by ACE inhibitors or ARBs improves the natriuretic response to ANP administration in rats with ACF [7, 8, 37]. Similar observations were reported by Villarreal and coworkers in the canine model of ACF [23]. Other neurohumoral vasoconstrictors, such as the SNS, may participate as well [41]. The cellular mechanisms by which the RAAS attenuates the natriuretic action of ANP are complex and incompletely understood. Based on our studies in rats with ACF, it appears that the interference with ANP signaling in CHF could involve changes at receptor level, the 2 nd messenger of the peptide, and beyond the 2 nd messenger of ANP [13, 62, 68, 69]. Smith and Lincoln [70] were the first to demonstrate in cultured vascular smooth muscle cells and mesangial cells that angiotensin II, and perhaps other vasoconstrictor $\mathrm{Ca}^{2+}$ mobilizing agents, may increase the degradation of cGMP, the 2nd messenger of ANP, by activation of $\mathrm{Ca}^{2+}$-dependent phosphodiesterase. This potential mechanism is of interest since we have demonstrated that urinary cGMP excretion is reduced in rats with ACF; however, cGMP generation in isolated glomeruli from ACF rats as tested in vitro in response to ANP remains intact [69]. Moreover, administration of the ARB losartan 
can restore the ANP-mediated cGMP excretion in ACF rats with decompensated $\mathrm{CHF}$, suggesting that interference in ANP signaling in this model occurs at a step beyond cGMP generation $[37,69]$.

The concept that urinary salt and water excretion is determined by the balance between ANP and the RAAS is important not only because it can elucidate the mechanisms of "ANP resistance" in CHF but because of its potential therapeutic implications. Indeed, potentiating the biologic effects of ANP in CHF may be achieved either by removing the influence of the RAAS or by enhancing the effects of ANP or its 2nd messenger cGMP. The latter approach utilizes pharmacologic agents that inhibit the enzymatic degradation of ANP by neutral endopeptidase (NEP), an endothelial cell surface metalloproteinase that is involved in the degradation of several regulatory peptides, including the natriuretic peptides. Combined NEP/ACE inhibitors, the so-called vasopeptidase inhibitors, reduce vasoconstriction and enhance vasodilatation and natriuresis apparently by blocking angiotensin II generation and the degradation of the natriuretic peptides [71]. Indeed, we have demonstrated that Omapatrilat, a drug belonging to the group of vasopeptidase inhibitors, improves both sodium balance and cardiac remodeling in rats with $\mathrm{ACF}$ and might be advantageous to ACE inhibitors for the treatment of decompensated CHF [72]. Finally, an early study by Wilkins and coworkers [73] demonstrated that administration of a selective cGMP phosphodiesterase inhibitor, M\&B-22948 increased urinary sodium excretion and restored the natriuretic response to exogenous and endogenous ANP in rats with ACF, supporting the notion that enhanced degradation of cGMP can limit the natriuresis induced by ANP in this model of CHF. The more recent development of highly selective and potent inhibitors of phosphodiesterase-5 (PDE-5) provides an opportunity to test the contribution of this pathway to the mechanism of blunted responsiveness to the natriuretic peptides in CHF [74]. Indeed, such a mechanism was found to be of importance in dogs with rapid pacing-induced chronic CHF [75]. Unfortunately, the efficacy of these agents was not tested in the rat model of ACF.

Two other important vasodilatory/natriuretic systems, namely, the nitric oxide (NO) and the vasodilatory prostaglandins, have been studied in rats with ACF, mainly in the context of regulation of renal blood flow (RBF) in experimental CHF, and therefore will be alluded to in the section on renal manifestations of rats with ACF.

\section{Renal Manifestations}

The kidney plays a key role in the pathogenesis of CHF $[36,76]$. The main changes observed in patients and in experimental models of CHF include alterations in the regulation of RBF and sodium and water excretion that can contribute to the development of positive sodium balance, edema formation, and deterioration into a state of decompensated heart failure. Over the years, our group and others have studied the renal manifestations in this rat model of CHF. The main observations are summarized in the following section.
A decrease in RBF is one of the earliest and most consistent finding in patients with CHF [76]. Traditionally, this decrease in renal perfusion has been attributed to a combination of several pathogenetic mechanisms: a reduction in the pumping capacity of the failing myocardium combined with compensatory activation of neurohormonal vasoconstrictor systems such as the RAAS, SNS and ADH $[36,76]$. We have shown repeatedly that RBF, measured directly by ultrasonic flowmetry, is reduced by more than $50 \%$ in rats with ACF [17] (see Table 1). Concomitant with the decrease in RBF there is also a decrease in glomerular filtration rate (GFR) that is more pronounced in CHF rats with decompensated CHF (Table 1). Our studies clearly underscore the importance of the RAAS in mediating the alterations in renal hemodynamics in this experimental model of CHF [11, 12]. As pointed out earlier, activation of the RAAS is one of the earliest compensatory neurohumoral responses to the decrease in the pumping capacity of the failing myocardium in CHF $[30,36]$. In particular, angII seems to play an important role in mediating the changes in renal hemodynamics in $\mathrm{CHF}$, in view of the unique sensitivity of the kidney to the vasoconstrictor action of this peptide on the afferent and efferent arterioles and on mesangial cells [77]. The importance of angII in mediating the decrease in RBF was shown in our previous study in which acute infusion of the ARB eprosartan resulted in a prompt and sustained increase in RBF in rats with ACF [12]. In addition to the RAAS other vasoconstrictors, such as increased SNS activity, may participate in mediating renal hypoperfusion although the role of the latter system was not studied by us in this model.

ET-1 is another potent vasoconstrictor implicated in the mediation of renal hypoperfusion in CHF. Artificial increase of plasma ET-1 levels in experimental animals to concentrations found in patients with CHF [78] is associated with significant reduction in RBF and increased vascular resistance. Bearing in mind that $\mathrm{CHF}$ is characterized by reduced RBF associated with increased vascular resistance along elevated levels of ET-1, it is appealing that a cause and effect relationship between these hemodynamic abnormalities and ET- 1 exists in this disease state. The role of the ET-1 system in mediating the alterations in renal hemodynamics in rats with ACF has been studied extensively by our group [79]. First, we showed that the intrarenal ET system is activated in ACF rats by demonstrating that the endothelin converting enzyme (ECE) is upregulated in the kidneys of rats with ACF [79-82]. Second, by using selective ETA and ETB receptor antagonists combined with RT-PCR and Western blot evaluation of the renal ETA and ETB receptor expression and immunoreactive levels, we showed that CHF is associated with altered regulation of intrarenal blood flow, which reflects alterations in expression and activity of the ET and NO systems. We further suggested that exaggerated NO activity in the medulla contributes to preservation of medullary blood flow in the face of cortical vasoconstriction in rats with ACF [80]. Third, we demonstrated that the ETA and ETB receptors are differentially regulated in the kidneys of ACF rats with compensated and decompensated CHF [81]. While compensated CHF was associated with 
upregulation of ETB in the collecting duct and vasa recta, decompensated $\mathrm{CHF}$ was accompanied with enhanced ETB abundance in the vasa recta and remarkable downregulation of this receptor subtype in the collecting duct. This suggested that upregulation of ETA may lead to a decrease in cortical blood flow, while upregulation of ETB in the vasa recta probably contributed to the preservation of medullary blood flow. Furthermore, downregulation of ETB in the collecting duct, only in rats with decompensated CHF, could contribute to sodium retention in that subgroup [81]. Finally, we studied the effects of chronic blockade of the ETA and ETB receptor by selective antagonist on renal hemodynamics and excretory functions in rats with ACF [82]. Chronic treatment with an ETA receptor blocker totally abolished the systemic and renal vasoconstriction caused by injected ET-1 in rats with ACF whereas a selective ETB receptor antagonist potentiated these effects. Chronic treatment of animals with congestive heart failure with ETA blocker did not influence daily sodium excretion whereas treatment with ETB antagonist significantly improved daily sodium excretion [82]. For the sake of clarity it should be mentioned that the use ET antagonists such as Darusentan did not improve the clinical manifestations an outcome in patients with CHF treated by conventional therapy [83]. This discrepancy between clinical and experimental CHF could be attributed to differences in the severity of and etiology of CHF, as well as the doses and time of drugs administration.

The control of RBF in experimental CHF is associated not only with alterations in the vasoconstrictor arm of the regulatory system. Indeed, one of the important breakthroughs in the last century was the discovery of role of endothelial cells in the regulation of blood flow and the recognition of the importance of locally released vasodilatory substances, in particular $\mathrm{NO}$, in the regulation of $\mathrm{RBF}$ and systemic hemodynamics [84]. In this regard, we demonstrated in rats with ACF an impaired endothelial-dependent vasorelaxation in response to acetylcholine administration, suggesting that the decrease in RBF is not related only to increased activity of vasoconstrictor systems but also reflects the failure of the endothelial-dependent NO action [11]. Moreover, similar to the mechanism of the impaired natriuretic response to ANP, increased activity of the RAAS played a key role in mediating this phenomenon since treatment with the ARB A-81988 resulted in almost a complete restoration of renal endothelial-dependent vasodilatation in this model [11]. We have also shown that the NO system plays a crucial role in the maintenance of intact blood perfusion to the renal medulla in rats with ACF, despite a significant decrease in total RBF [80]. This is achieved by upregulation of the endothelial-derived NO synthase in the renal medulla, suggesting that exaggerated $\mathrm{NO}$ activity in the medulla contributes to preservation of medullary blood flow in the face of cortical vasoconstriction in CHF.

Another important system that participates in the regulation of RBF in animals with ACF is the renal prostaglandin system. Early studies demonstrated that prostaglandins are involved in the maintenance of RBF and GFR in the canine model of ACF, and that indomethacin administration produced striking reductions in renal hemodynamic function [21]. More recent studies by our group disclosed the importance of the system in the maintenance of renal medullary blood flow in rats with ACF [85]. We evaluated the relative expression and immunoreactive levels of the cyclooxygenases 1 and 2 (COX-1 and COX-2), the enzymes involved in the synthesis of the PGs from arachidonic acid, in the renal cortex and medulla of rats with ACF, and examined the effects of selective and nonselective inhibitors of these COX isoforms on cortical and medullary blood flow. We found that both COX-1 and COX-2 are predominantly expressed in the renal medulla and that rats with ACF display selective overexpression of COX-2. The latter may represent a mechanism aimed at defending medullary blood flow in the face of a decrease in total and cortical blood flow during the development of CHF [85].

In addition to changes in renal hemodynamics, rats with ACF are characterized also by alterations in renal salt and water retention. The mechanisms leading to salt retention and the interactions between the RAAS and other vasoconstrictors with ANP in determining the final balance of salt excretion have been described in early parts of this review. There is, however, abundant evidence that both clinical and experimental $\mathrm{CHF}$ are associated with alterations in the $\mathrm{ADH}$-renal water transport axis, independent of regulation of renal sodium transport. The most recognized renal effect of $\mathrm{ADH}$ in $\mathrm{CHF}$ is the development of hyponatremia which usually occurs in advanced stages of the disease and may occur at concentrations much lower than those required for vasoconstriction [48]. This phenomenon has been attributed to water retention by the kidney due to sustained release of $\mathrm{ADH}$, irrespective of plasma osmolality. Mulinari and associates [86] have demonstrated that administration of an $\mathrm{ADH}$ antagonist with dual $\mathrm{V}_{1} / \mathrm{V}_{2}$ antagonism to rats with ischemic $\mathrm{CHF}$ induced by left coronary ligation resulted in a rise in cardiac output, a decline in PVR, and an increase in urine output of 4 - to 10 -fold over baseline, confirming the role of $\mathrm{ADH}$ in the water retention and the increased vascular resistance of $\mathrm{CHF}$. Recent reports have provided further insights into the mechanisms of $\mathrm{ADH}$-mediated water retention in experimental CHF. These studies in animal models of CHF have also demonstrated an increased renal expression of AQP2 in these animals, suggesting that this may also contribute to the enhanced water reabsorption in the CD [87]. It is therefore not surprising that initial studies have shown that administration of $\mathrm{V}_{2}$ vasopressin receptor antagonists of peptidic and nonpeptidic nature to rats with inferior vena cava constriction [88], dogs with CHFinduced by rapid pacing [89], and rats with $\mathrm{CHF}$-induced by coronary ligation [48] have resulted in correction of the impaired urinary dilution in response to acute water load. The mechanism underlying these expected findings rely on the fact AQP2 are expressed in the collecting duct and mediate the antidiuretic action of $\mathrm{ADH}[88,90]$ Furthermore, the expression of AQP2 and its immunoreactive levels has been reported to be elevated in the kidney of rats with experimental CHF induced by coronary artery ligation [91, 92]. Oral treatment of these rats with $\mathrm{V}_{2}$ antagonist (OPC31260) induced significant diuresis, a decrease in urinary osmolarity and increased plasma osmolarity, which were associated 
with downregulation of renal AQP-2 [91]. These findings indicate a major role for $\mathrm{ADH}$ in the upregulation of AQP2 water channels and subsequently enhanced water retention in experimental CHF. Similarly, we have demonstrated that acute administration of SR $121463 \mathrm{~B}\left(\mathrm{~V}_{2}\right.$ antagonist), but not SR 49059 ( $V_{1}$ antagonist), to rats with ACF caused a fourfold increase in urinary flow rate [44]. The diuretic effects of SR $121463 \mathrm{~B}$ were associated with a significant decline in urinary osmolality and insignificant change of $\mathrm{Na}^{+}$excretion. In line with its acute effects, chronic administration (4 weeks) of SR $121463 \mathrm{~B}$ to $\mathrm{CHF}$ rats increased daily urinary volume up to 5 -fold throughout the treatment period. In agreement with the studies in experimental animals, several recent clinical studies have demonstrated that chronic treatment with selective $V_{2}$ and dual $V_{1 a} / V_{2}$ antagonists may be beneficial in the correction of hyponatremia in CHF $[49,93,94]$. For instance, administration of the oral selective $V_{2}$ receptor antagonist VPA-985 to patients with CHF for seven days at incremental doses induced significant diuretic response accompanied by increase in plasma $\mathrm{Na}^{+}$concentration and decreased urine osmolarity [95]. Similarly, when YM087, an orally $V_{1} / V_{2}$ antagonist was given to orally to patients with CHF it increased plasma $\mathrm{Na}^{+}$reduced osmolarity of the urine and increased urine output $[93,96]$. Collectively, these data suggest that $\mathrm{ADH}$ is involved in the pathogenesis of water retention and hyponatremia that characterize $\mathrm{CHF}$ including rats with decompensated $\mathrm{CHF}$ due to ACF, and that vasopressin receptor antagonist results in remarkable diuresis in both experimental and clinical CHF.

\section{Cardiac Manifestation}

Rats with ACF are characterized by cardiac hypertrophy and dilatation, as well as myocardial remodeling [6-12] Cardiac hypertrophy is also a major characteristic of many cardiovascular disorders and is considered to be a major risk factor of cardiovascular mortality and morbidity [97]. The increased ventricular mass is a general adaptive response to states of cardiac hyperfunction [10,31,37, 98-100], and is observed in a wide range of physiological and pathologic states, including pressure overload, volume overload, and excessive exposure to neurohumoral and metabolic stimuli. It should be emphasized that the biochemical and morphological responses of myocytes depends on the specific inciting stimulus. For example, thyroid hormone-induced hypertrophy in myocytes differs from that induced by $\alpha$-and $\beta$-adrenergic stimuli $[101,102]$. Further, the characteristics of the cardiac hypertrophic response differ among various forms of exercise, aortic stenosis [103], genetic hypertension, or hypertension caused by renal artery stenosis [104]. Therefore, several animal models were developed to create cardiovascular diseases, CHF, and cardiac hypertrophy-based on the etiology of the corresponding clinical situations. The dynamic nature of CHF is exemplified by the observations that at its first stages, hypertrophy is an appropriate and adaptive response to elevate pressure/volume overload; however, it often progresses to the decompensated stage and CHF [98]. With the progression of the initial stimulus, a transition occurs in which an irreversible decompensation in cardiac function takes place, leading to heart failure, as well as to an increased tendency to develop sodium retention, edema, dyspnea, and arrhythmias $[105,106]$. The trigger for this transition from compensated hypertrophy to decompensation is unknown. By macroscopic morphology, decompensated hypertrophy and heart failure are usually characterized by ventricular dilation [106].

ACF model has become the most frequently used technique to induce volume overload hypertrophy followed by heart failure in rats [107-109]. Several studies have demonstrated that a surgically installed fistula between the aorta and the vena cava causes a drastic volume overload on the heart, which results in marked left and right ventricular hypertrophy few weeks after surgery $[15,110]$. In fact, studies from our laboratory have shown remarkable cardiac hypertrophy/remodeling, in correlation with the severity of the heart failure, even after one week from the creation of ACF $[10,12,31]$. For instance, heart/body weight, an index of cardiac hypertrophy, increased by $41 \%$ and $75 \%$ in rats with compensated and decompensated CHF, respectively, 7 days after the placement of surgical fistula between the aorta and vena cava (Figure 3). Although various causes of cardiac remodeling share several molecular, biochemical and mechanical pathways, different stimuli induce diverse ventricular remodeling patterns. In general, the hypertrophic pattern in response to volume overload differs from that in pressure overload, both morphologically and biochemically $[110,111]$. For example, pressure overload-induced cardiac hypertrophy occurs in many clinical settings that include hypertension, mitral valve stenosis, and aortic valve stenosis. When subjected to one of these negative stimuli, the heart undergoes concentric remodeling due to increased cardiomyocytes diameter in order to normalize wall stress due to the increase in pressure exerted on the cardiac tissue [112-114] (Figure 4). In contrast, volume overload results in cardiomyocytes lengthening and eccentric hypertrophy (Figure 4) $[113,114]$. The latter condition is caused by anemia, heart block, regurgitant mitral or aortic valves, atrial or ventricular septal defects, or ACF [115]. Indeed, rats with ACF develop eccentric hypertrophy, which results in left ventricular (LV) dilatation and a concurrent elevation in stroke volume in order to compensate for the excessive blood volume delivered to, or remaining in the LV (Figure 4(b)). Dilatation of the LV chamber occurs via elongation of the surrounding myocytes, which results from sarcomeric replication in series [115]. The differences between cardiac remodeling in pressure and volume overload are largely influenced by hemodynamic load, neurohumoral activation and additional factors such as endothelin, cytokines, nitric oxide (NO) production and oxidative stress [116]. One of the main vasoconstrictor neurohumoral systems, which play a key role in the pathophysiology cardiac hypertrophy in CHF, is the renin-angiotensin-aldosterone system (RAAS) [36, $117,118]$. Prolonged activation of the RAAS has direct deleterious actions on the myocardium, independent of its systemic hemodynamic effects [119]. Specifically, angiotensin II (Ang II) has been shown to stimulate myocyte hypertrophy and to enhance fibrosis and apoptosis, leading ultimately to 


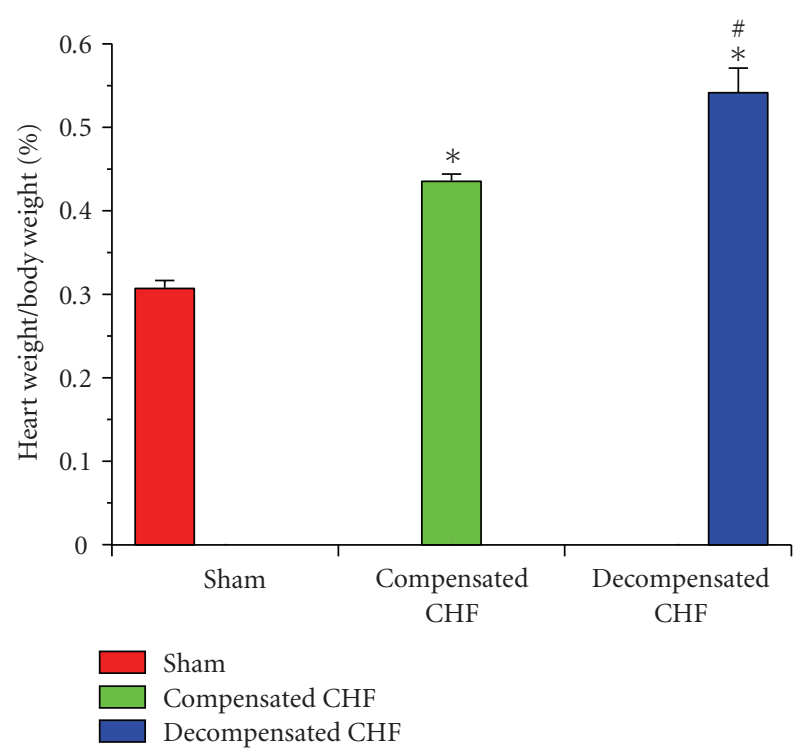

FIgure 3: Cardiac hypertrophy expressed as heart weight/body weight ratio (HW/BW\%) in rats with compensated and decompensated $\mathrm{CHF}$, one week after the placement of AV fistula. ${ }^{*} P<.05$ versus sham-operated rats; ${ }^{\#} P<.05$ versus compensated rats with AV fistula. Values are means \pm SEM.

progressive remodeling and further deterioration in cardiac performance [120]. The adverse contribution of aldosterone to the functional and structural alterations of the failing heart was elegantly demonstrated by Suzuki et al. [121]. These authors showed that eplerenone, a specific aldosterone antagonist, prevented progressive LV systolic and diastolic dysfunction in association with reducing interstitial fibrosis, cardiomyocyte hypertrophy and LV chamber sphericity in dogs with CHF induced by intracoronary microembolizations. Similarly, Delyani et al. [122] reported that eplerenone, attenuated the development of ventricular remodeling and reactive but not reparative fibrosis after myocardial infarction in rats. In line with these adverse effects of the RAAS on cardiac hypertrophy and remodeling in low cardiac output CHF models, we and others demonstrated that ACE, Ang II and aldosterone inhibition by enalapril, eprosartan, or spironolactone, respectively, reduced cardiac hypertrophy and fibrosis and at the same time caused a significant increase in urinary sodium excretion when administered chronically in rats with ACF [7-9, 12, 32].

Additional system of special interest in the pathogenesis of cardiac hypertrophy and renal dysfunction in CHF is the natriuretic peptides system. As mentioned above, plasma levels of ANP are chronically elevated in several pathological conditions, including CHF and are found to be related to atrial pressure [123-125]. Actually, the highest concentrations of ANP in the circulation occur in CHF [123125]. Moreover, plasma levels of ANP in CHF have been found to correlate with the severity of cardiac failure, as well as with the elevated atrial pressure and other parameters of left ventricular dysfunction. In rats with experimental CHF due to ACF, we reported high comparable levels of plasma

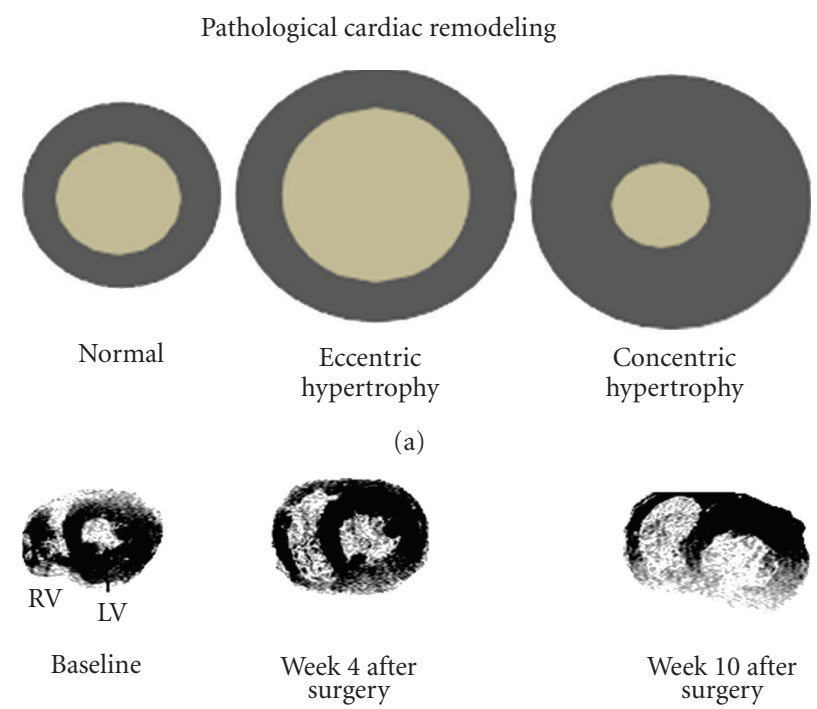

(b)

FIGURE 4: (a) A scheme showing pathological cardiac remodeling, eccentric versus concentric hypertrophy. (b) MRI images of hearts from sham controls and rats with aortocaval fistula at different time points. Notice that rats with AV fistula exhibited cardiac hypertrophy dilation compared with sham controls.

ANP in both compensated and decompensated CHF [7] (Table 1). Similar to ANP, plasma levels of BNP, which is produced mainly by the ventricles in response to ventricular stretch and pressure overload [126, 127], are elevated in patients with $\mathrm{CHF}$ in proportion to the severity of the myocardial systolic and diastolic dysfunction. Hoffman et al. [6] demonstrated that rats ACF have high levels of BNP in the plasma. Similarly, the enhanced plasma levels of BNP coincides with overexpression of BNP in the myocardium of rats with ACF [128], corresponding with the high volume overload and cardiac hypertrophy characterizing this model of CHF.

While cardiac hypertrophy and ventricular dilation develop rapidly (within 1-2 weeks) in response to volume overload in animals with ACF $[9,10,12,13]$, the evolvement of heart failure in this model may take several weeks to few months. In this regard, Brower et al. [129] examined the effect of the creation of ACF induced by 18-guage needle that was inserted into the exposed abdominal aorta and advanced through the medial wall into the vena cava to create a fistula, on cardiac hypertrophy and ventricular dilation $1,2,3,5$, and 8 weeks post ACF placement. Progressive hypertrophy and left and right ventricular hypertrophy in association with decline in ventricular stiffness and contractility occurred throughout the followup period. Interestingly, systolic function was preserved due to the compensatory remodeling of the myocardium. Similarly, Huang et al. [130] have shown that cardiac output is maintained at normal or even enhanced levels during the early phase of ACF (i.e., $<8$ weeks). According to Brower et al. [129] reports, only 3\% of the rats with ACF progress toward overt CHF during the 8 weeks post the fistula placement. However, the increase 
in BW and lung weight seen in about $50 \%$ of rats with ACF, suggests a consistent development of CHF. When rats with ACF were monitored for longer periods, namely, 1621 weeks post ACF, the mortality rate was $80 \%$ due to CHF, which occurred once the myocardial hypertrophic response was exhausted [131, 132]. Collectively, these studies suggest that the development of decompensated hypertrophy or CHF occurs in low percentage at least 8 weeks after the creation of ACF, but requires about 16 weeks to reach its maximal incidence.

Keen evidence for the responsibility of the ACF for the development of cardiac, renal, and neurohormonal perturbations is derived from several studies where the effect of ACF closure on these parameters was studied. Surgical repair of the ACF in the symptomatic patient resulted in resolution of the CHF and reversed the dilatation of the heart ventricles $[18,26,133]$. Specifically, closure of an AV fistula, induces both characteristic diuretic and natriuretic responses in experimental animals $[10,18,133]$ and reversal of the clinical signs of CHF in patients [26]. Likewise, complete reversal of the hemodynamic abnormalities, including restoration of peripheral vascular resistance, diastolic pressure, and mean arterial pressure [134], in association with reduced plasma levels of ANP were observed [135]. However, Zucker et al. [136] demonstrated in a canine model that closure of AV fistula, although resulting in significant regression of cardiac dilatation, did not completely restore heart size to normal. This most likely indicates permanent cardiac structural changes in this experimental model.

In summary, the ACF-induced CHF in rats is an inexpensive and rapidly evolved model of cardiac hypertrophy and remodeling. Since this model mimics high cardiac output clinical heart failure, it may be suitable to study myocardial alterations, mainly cardiac hypertrophy characterizing these patients. However, since different mechanisms underlie pressure-as compared to volume overload-induced cardiac remodeling, this experimental model may not be appropriate to investigate cardiac function and hypertrophy in pressure overload clinical settings.

\section{Acknowledgment}

The authors are grateful for Dr. Konstantin Gurbanov for the preparation of the MRI pictures.

\section{References}

[1] W. B. Kannel, "Current status of the epidemiology of heart failure," Current Cardiology Reports, vol. 1, no. 1, pp. 11-19, 1999.

[2] M. Jessup and S. Brozena, "Heart failure," The New England Journal of Medicine, vol. 348, no. 20, pp. 2007-2018, 2003.

[3] G. Hasenfuss, "Animal models of human cardiovascular disease, heart failure and hypertrophy," Cardiovascular Research, vol. 39, no. 1, pp. 60-76, 1998.

[4] K. O. Stumpe, H. Solle, H. Klein, and F. Kruck, "Mechanism of sodium and water retention in rats with experimental heart failure," Kidney International, vol. 4, no. 5, pp. 309-317, 1973.
[5] K. O. Stumpe, B. Reinelt, C. Ressel, H. Klein, and F. Kruck, "Urinary sodium excretion and proximal tubule reabsorption in rats with high output heart failure," Nephron, vol. 12, no. 4, pp. 261-274, 1974.

[6] A. Hoffman, E. Grossman, and H. R. Keiser, "Increased plasma levels and blunted effects of brain natriuretic peptide in rats with congestive heart failure," American Journal of Hypertension, vol. 4, no. 7 I, pp. 597-601, 1991.

[7] J. Winaver, A. Hoffman, J. C. Burnett, and A. Haramati, "Hormonal determinants of sodium excretion in rats with experimental high-output heart failure," American Journal of Physiology, vol. 254, no. 5, pp. R776-R784, 1988.

[8] Z. Abassi, A. Haramati, A. Hoffman, J. C. Burnett, and J. Winaver, "Effect of converting-enzyme inhibition on renal response to ANF in rats with experimental heart failure," American Journal of Physiology, vol. 259, no. 1, pp. R84-R89, 1990.

[9] T. Karram, A. Abbasi, S. Keidar et al., "Effects of spironolactone and eprosartan on cardiac remodeling and angiotensinconverting enzyme isoforms in rats with experimental heart failure," American Journal of Physiology, vol. 289, no. 4, pp. H1351-H1358, 2005.

[10] Z. A. Abassi, S. Brodsky, T. Karram, I. Dobkin, J. Winaver, and A. Hoffman, "Temporal changes in natriuretic and antinatriuretic systems after closure of a large arteriovenous fistula," Cardiovascular Research, vol. 51, no. 3, pp. 567-576, 2001.

[11] Z. A. Abassi, K. Gurbanov, S. E. Mulroney et al., "Impaired nitric oxide-mediated renal vasodilation in rats with experimental heart failure: role of angiotensin II," Circulation, vol. 96, no. 10, pp. 3655-3664, 1997.

[12] S. Brodsky, K. Gurbanov, Z. Abassi et al., "Effects of eprosar$\tan$ on renal function and cardiac hypertrophy in rats with experimental heart failure," Hypertension, vol. 32, no. 4, pp. 746-752, 1998.

[13] J. Winaver, A. Hoffman, Z. Abassi, and A. Haramati, "Does the heart's hormone, ANP, help in congestive heart failure?" News in Physiological Sciences, vol. 10, pp. 247-253, 1995.

[14] T. Karram, A. Hoffman, B. Bishara et al., "Induction of cardiac hypertrophy by a controlled reproducible sutureless aortocaval shunt in the mouse," Journal of Investigative Surgery, vol. 18, no. 6, pp. 325-334, 2005.

[15] R. Garcia and S. Diebold, "Simple, rapid, and effective method of producing aortocaval shunts in the rat," Cardiovascular Research, vol. 24, no. 5, pp. 430-432, 1990.

[16] M. Huang, M. H. LeBlanc, and R. L. Hester, "Evaluation of the needle technique for producing an arteriovenous fistula," Journal of Applied Physiology, vol. 77, no. 6, pp. 2907-2911, 1994.

[17] Z. Abassi, B. Francis, J. Wessale, E. Ovcharenko, J. Winaver, and A. Hoffman, "Effects of endothelin receptors ET and ET blockade on renal haemodynamics in normal rats and in rats with experimental congestive heart failure," Clinical Science, vol. 103, supplement 48, pp. 245S-248S, 2002.

[18] J. G. Hilton, D. M. Kanter, D. R. Hays et al., "The effect of acute arteriovenous fistula on renal functions," The Journal of Clinical Investigation, vol. 34, pp. 732-736, 1955.

[19] I. H. Zucker, A. M. Earle, and J. P. Gilmore, "The mechanism of adaptation of left atrial stretch receptors in dogs with chronic congestive heart failure," Journal of Clinical Investigation, vol. 60, no. 2, pp. 323-331, 1977.

[20] E. G. Schneider, T. P. Dresser, R. E. Lynch, and F. G. Knox, "Sodium reabsorption by proximal tubule of dogs 
with experimental heart failure," The American Journal of Physiology, vol. 220, no. 4, pp. 952-957, 1971.

[21] D. Villarreal, J. O. Davis, R. H. Freeman, J. R. Dietz, and S. F. Echtenkamp, "Effects of indomethacin in conscious dogs with experimental high-output heart failure," The American Journal of Physiology, vol. 245, no. 6, pp. H942-H946, 1983.

[22] D. Villarreal, R. H. Freeman, and M. W. Brands, "DOCA administration and atrial natriuretic factor in dogs with chronic heart failure," American Journal of Physiology, vol. 257, no. 3, pp. H739-H745, 1989.

[23] D. Villarreal, R. H. Freeman, and R. A. Johnson, "Captopril enhances renal responsiveness to ANF in dogs with compensated high-output heart failure," American Journal of Physiology, vol. 262, no. 3, pp. R509-R516, 1992.

[24] D. Villarreal, R. H. Freeman, and R. A. Johnson, "Neurohumoral modulators and sodium balance in experimental heart failure," American Journal of Physiology, vol. 264, no. 4, pp. H1187-H1193, 1993.

[25] L. B. Laplace, "Observations on the effect of an arteriovenous fistula on the human circulation," The American Journal of the Medical Sciences, vol. 189, pp. 497-507, 1935.

[26] F. H. Epstein, R. S. Post, and M. Mcdowell, "The effects of an arteriovenous fistula on renal hemodynamics and electrolyte excretion," The Journal of Clinical Investigation, vol. 32, no. 3, pp. 233-241, 1953.

[27] F. H. Epstein, O. W. Shadle, T. B. Ferguson, and M. E. Mcdowell, "Cardiac output and intracardiac pressures in patients with arteriovenous fistulas," The Journal of Clinical Investigation, vol. 32, no. 6, pp. 543-547, 1953.

[28] S. F. Flaim, W. J. Minteer, and R. Zelis, "Acute effects of arterio-venous shunt on cardiovascular hemodynamics in rat," Pflugers Archiv European Journal of Physiology, vol. 385, no. 3, pp. 203-209, 1980.

[29] Z. Liu, D. R. Hilbelink, W. B. Crockett, and A. M. Gerdes, "Regional changes in hemodynamics and cardiac myocyte size in rats with aortocaval fistulas: 1. Developing and established hypertrophy," Circulation Research, vol. 69, no. 1, pp. 52-58, 1991.

[30] L. Watkins Jr., J. A. Burton, and E. Haber, "The renin angiotensin aldosterone system in congestive failure in conscious dogs," Journal of Clinical Investigation, vol. 57, no. 6, pp. 1606-1617, 1976.

[31] F. Pieruzzi, Z. A. Abassi, and H. R. Keiser, "Expression of renin-angiotensin system components in the heart, kidneys, and lungs of rats with experimental heart failure," Circulation, vol. 92, no. 10, pp. 3105-3112, 1995.

[32] M. Ruzicka, B. Yuan, E. Harmsen, and F. H. H. Leenen, “The renin-angiotensin system and volume overload-induced cardiac hypertrophy in rats: effects of angiotensin converting enzyme inhibitor versus angiotensin II receptor blocker," Circulation, vol. 87, no. 3, pp. 921-930, 1993.

[33] D. Villarreal and R. H. Freeman, "ANF and the reninangiotensin system in the regulation of sodium balance: longitudinal studies in experimental heart failure," Journal of Laboratory and Clinical Medicine, vol. 118, no. 6, pp. 515522, 1991.

[34] M. Packer, "Adaptive and maladaptive actions of angiotensin II in patients with severe congestive heart failure," American Journal of Kidney Diseases, vol. 10, no. 1, pp. 66-73, 1987.

[35] R. W. Schrier, A. Masoumi, and E. Elhassan, "Aldosterone: role in edematous disorders, hypertension, chronic renal failure, and metabolic syndrome," Clinical Journal of the American Society of Nephrology, vol. 5, no. 6, pp. 1132-1140, 2010.
[36] V. J. Dzau, "Renal and circulatory mechanisms in congestive heart failure," Kidney International, vol. 31, no. 6, pp. 14021415, 1987.

[37] Z. A. Abassi, G. Kelly, E. Golomb, H. Klein, and H. R. Keiser, "Losartan improves the natriuretic response to ANF in rats with high- output heart failure," Journal of Pharmacology and Experimental Therapeutics, vol. 268, no. 1, pp. 224-230, 1994.

[38] R. Willenbrock, M. Scheuermann, G. Thibault et al., "Angiotensin inhibition and atrial natriuretic peptide release after acute volume expansion in rats with aortocaval shunt," Cardiovascular Research, vol. 42, no. 3, pp. 733-742, 1999.

[39] K. L. Skorecki, J. Winaver, and Z. A. Abassi, "Extracellular fluid and edema formation," in The Kidney, B. M. Brenner, Ed., pp. 398-458, Saunders Elsevier, Philadelphia, Pa, USA, 2008.

[40] M. J. Niebauer, M. J. Holmberg, and I. H. Zucker, "Aortic baroreceptor characteristics in dogs with chronic high output failure," Basic Research in Cardiology, vol. 81, no. 2, pp. 111122, 1986.

[41] D. Villarreal, R. H. Freeman, R. A. Johnson, and J. C. Simmons, "Effects of renal denervation on postprandial sodium excretion in experimental heart failure," American Journal of Physiology, vol. 266, no. 5, pp. R1599-R1604, 1994.

[42] G. L. Robertson, "Physiology of ADH secretion," Kidney International, vol. 32, no. 21, pp. S20-S26, 1987.

[43] L. Bankir, "Antidiuretic action of vasopressin: quantitative aspects and interaction between V1a and V2 receptormediated effects," Cardiovascular Research, vol. 51, no. 3, pp. 372-390, 2001.

[44] B. Bishara, H. Shiekh, T. Karram et al., "Effects of novel vasopressin receptor antagonists on renal function and cardiac hypertrophy in rats with experimental congestive heart failure," Journal of Pharmacology and Experimental Therapeutics, vol. 326, no. 2, pp. 414-422, 2008.

[45] S. R. Goldsmith, G. S. Francis, and A. W. Cowley, "Increased plasma arginine vasopressin levels in patients with congestive heart failure," Journal of the American College of Cardiology, vol. 1, no. 6, pp. 1385-1390, 1983.

[46] S. R. Goldsmith and M. Gheorghiade, "Vasopressin antagonism in heart failure," Journal of the American College of Cardiology, vol. 46, no. 10, pp. 1785-1791, 2005.

[47] R. W. Schrier, "Pathogenesis of sodium and water retention in high-output and low-output cardiac failure, nephrotic syndrome, cirrhosis, and pregnancy. II," New England Journal of Medicine, vol. 319, no. 17, pp. 1127-1134, 1988.

[48] P. Y. Martin and R. W. Schrier, "Sodium and water retention in heart failure: pathogenesis and treatment," Kidney International, Supplement, vol. 51, no. 59, pp. S57-S61, 1997.

[49] M. Gheorghiade, W. A. Gattis, C. M. O'Connor et al., "Effects of tolvaptan, a vasopressin antagonist, in patients hospitalized with worsening heart failure: a randomized controlled trial," Journal of the American Medical Association, vol. 291, no. 16, pp. 1963-1971, 2004.

[50] T. Masaki, "Possible role of endothelin in endothelial regulation of vascular tone," Annual Review of Pharmacology and Toxicology, vol. 35, pp. 235-255, 1995.

[51] D. E. Kohan, "The renal medullary endothelin system in control of sodium and water excretion and systemic blood pressure," Current Opinion in Nephrology and Hypertension, vol. 15, no. 1, pp. 34-40, 2006.

[52] E. R. Levin, "Endothelins," New England Journal of Medicine, vol. 333, no. 6, pp. 356-363, 1995. 
[53] P. M. Vanhoutte, "Endothelium-dependent responses in congestive heart failure," Journal of Molecular and Cellular Cardiology, vol. 28, no. 11, pp. 2233-2240, 1996.

[54] A. L. Clavell and J. C. Burnett, "Physiologic and pathophysiologic roles of endothelin in the kidney," Current Opinion in Nephrology and Hypertension, vol. 3, no. 1, pp. 66-72, 1994.

[55] M. P. Love and J. J. V. McMurray, "Endothelin in chronic heart failure: current position and future prospects," Cardiovascular Research, vol. 31, no. 5, pp. 655-674, 1996.

[56] J. J. McMurray, S. G. Ray, I. Abdullah, H. J. Dargie, and J. J. Morton, "Plasma endothelin in chronic heart failure," Circulation, vol. 85, no. 4, pp. 1374-1379, 1992.

[57] T. G. Von Lueder, H. Kjekshus, T. Edvardsen et al., "Mechanisms of elevated plasma endothelin-1 in CHF: congestion increases pulmonary synthesis and secretion of endothelin1," Cardiovascular Research, vol. 63, no. 1, pp. 41-50, 2004.

[58] L. A. Brown, D. J. Nunez, C. I. O. Brookes, and M. R. Wilkins, "Selective increase in endothelin-1 and endothelin A receptor subtype in the hypertrophied myocardium of the aorto-venacaval fistula rat," Cardiovascular Research, vol. 29, no. 6, pp. 768-774, 1995.

[59] P. G. Cavero, W. L. Miller, D. M. Heublein, K. B. Margulies, and J. C. Burnett, "Endothelin in experimental congestive heart failure in the anesthetized dog," American Journal of Physiology, vol. 259, no. 2, pp. F312-F317, 1990.

[60] G. Boerrigter and J. C. Burnett, "Recent advances in natriuretic peptides in congestive heart failure," Expert Opinion on Investigational Drugs, vol. 13, no. 6, pp. 643-652, 2004.

[61] R. R. Brandt, R. S. Wright, M. M. Redfield, and J. C. Burnett, "Atrial natriuretic peptide in heart failure," Journal of the American College of Cardiology, vol. 22, no. 4, pp. 86A-92A, 1993.

[62] A. Hoffman, J. C. Burnett, A. Haramati, and J. Winaver, "Effects of atrial natriuretic factor in rats with experimental high-output heart failure," Kidney International, vol. 33, no. 3, pp. 656-661, 1988.

[63] D. Villarreal, R. H. Freeman, and R. A. Johnson, "Renal effects of ANF (95-126), a new atrial peptide analogue, in dogs with experimental heart failure," American Journal of Hypertension, vol. 4, no. 6, pp. 508-515, 1991.

[64] R. Willenbrock, I. Pagel, M. Scheuermann et al., "Renal function in high-output heart failure in rats: role of endogenous natriuretic peptides," Journal of the American Society of Nephrology, vol. 10, no. 3, pp. 572-580, 1999.

[65] J. C. Burnett Jr., P. C. Kao, and D. C. Hu, "Atrial natriuretic peptide elevation in congestive heart failure in the human," Science, vol. 231, no. 4742, pp. 1145-1147, 1986.

[66] G. A. J. Riegger, D. Elsner, E. P. Kromer et al., "Atrial natriuretic peptide in congestive heart failure in the dog: plasma levels, cyclic guanosine monophosphate, ultrastructure of atrial myoendocrine cells, and hemodynamic, hormonal, and renal effects," Circulation, vol. 77, no. 2, pp. 398-406, 1988.

[67] M. E. Lee, W. L. Miller, B. S. Edwards, and J. C. Burnett, "Role of endogenous atrial natriuretic factor in acute congestive heart failure," Journal of Clinical Investigation, vol. 84, no. 6, pp. 1962-1966, 1989.

[68] H. Yechieli, L. Kahana, A. Haramati, A. Hoffman, and J. Winaver, "Regulation of renal glomerular and papillary ANP receptors in rats with experimental heart failure," American Journal of Physiology, vol. 265, no. 1, pp. F119-F125, 1993.

[69] Z. Abassi, J. C. Burnett, E. Grushka, A. Hoffman, A. Haramati, and J. Winaver, "Atrial natriuretic peptide and renal
cGMP in rats with experimental heart failure," American Journal of Physiology, vol. 261, no. 4, pp. R858-R864, 1991.

[70] J. B. Smith and T. M. Lincoln, "Angiotensin decreases cyclic GMP accumulation produced by atrial natriuretic factor," American Journal of Physiology, vol. 253, no. 1, pp. C147C150, 1987.

[71] R. Corti, J. C. Burnett Jr., J. L. Rouleau, F. Ruschitzka, and T. F. Lüscher, "Vasopeptidase inhibitors: a new therapeutic concept in cardiovascular disease?" Circulation, vol. 104, no. 15, pp. 1856-1862, 2001.

[72] Z. A. Abassi, A. Yahia, S. Zeid et al., "Cardiac and renal effects of omapatrilat, a vasopeptidase inhibitor, in rats with experimental congestive heart failure," American Journal of Physiology, vol. 288, no. 2, pp. H722-H728, 2005.

[73] M. R. Wilkins, S. L. Settle, P. T. Stockmann, and P. Needleman, "Maximizing the natriuretic effect of endogenous atriopeptin in a rat model of heart failure," Proceedings of the National Academy of Sciences of the United States of America, vol. 87, no. 16, pp. 6465-6469, 1990.

[74] S. D. Katz, "Potential role of type 5 phosphodiesterase inhibition in the treatment of congestive heart failure," Congestive Heart Failure, vol. 9, no. 1, pp. 9-15, 2003.

[75] H. H. Chen, B. K. Huntley, J. A. Schirger, A. Cataliotti, and J. C. Burnett, "Maximizing the renal cyclic 3'-5'-guanosine monophosphate system with type $\mathrm{V}$ phosphodiesterase inhibition and exogenous natriuretic peptide: a novel strategy to improve renal function in experimental overt heart failure," Journal of the American Society of Nephrology, vol. 17, no. 10, pp. 2742-2747, 2006.

[76] A. C. Barger, F. P. Muldowney, and M. R. Liebowitz, "Role of the kidney in the pathogenesis of congestive heart failure," Circulation, vol. 20, pp. 273-285, 1959.

[77] I. Ichikawa, T. Yoshioka, A. Fogo, and V. Kon, "Role of angiotensin II in altered glomerular hemodynamics in congestive heart failure," Kidney International, vol. 38, no. 30, pp. S123-S126, 1990.

[78] A. Lerman, S. H. Kubo, L. K. Tschumperlin, and J. C. Burnett, "Plasma endothelin concentrations in humans with endstage heart failure and after heart transplantation," Journal of the American College of Cardiology, vol. 20, no. 4, pp. 849853, 1992.

[79] Z. Abassi, J. Winaver, I. Rubinstein et al., "Renal endothelinconverting enzyme in rats with congestive heart failure," Journal of Cardiovascular Pharmacology, vol. 31, supplement 1, pp. S31-S34, 1998.

[80] Z. Abassi, K. Gurbanov, I. Rubinstein, O. S. Better, A. Hoffman, and J. Winaver, "Regulation of intrarenal blood flow in experimental heart failure: role of endothelin and nitric oxide," American Journal of Physiology, vol. 274, no. 4, pp. F766-F774, 1998

[81] B. N. Francis, Z. Abassi, S. Heyman, J. Winaver, and A. Hoffman, "Differential regulation of ET(A) and ET(B) in the renal tissue of rats with compensated and decompensated heart failure," Journal of Cardiovascular Pharmacology, vol. 44, supplement 1, pp. S362-S365, 2004.

[82] B. Francis, J. Winaver, T. Karram, A. Hoffman, and Z. Abassi, "Renal and systemic effects of chronic blockade of ET(A) or ET(B) in normal rats and animals with experimental heart failure," Journal of Cardiovascular Pharmacology, vol. 44, supplement 1, pp. S54-S58, 2004.

[83] P. I. Anand, P. J. McMurray, P. J. N. Cohn et al., "Longterm effects of darusentan on left-ventricular remodelling and clinical outcomes in the Endothelin Receptor Antagonist Trial in Heart Failure (EARTH): randomised, double-blind, 
placebo-controlled trial," The Lancet, vol. 364, no. 9431, pp. 347-354, 2004.

[84] R. F. Furchgott and J. V. Zawadzki, "The obligatory role of endothelial cells in the relaxation of arterial smooth muscle by acetylcholine," Nature, vol. 288, no. 5789, pp. 373-376, 1980.

[85] Z. Abassi, S. Brodsky, O. Gealekman, I. Rubinstein, A. Hoffman, and J. Winaver, "Intrarenal expression and distribution of cyclooxygenase isoforms in rats with experimental heart failure," American Journal of Physiology, vol. 280, no. 1, pp. F43-F53, 2001.

[86] R. A. Mulinari, I. Gavras, Y. X. Wang, R. Franco, and H. Gavras, "Effects of a vasopressin antagonist with combined antipressor and antiantidiuretic activities in rats with left ventricular dysfunction," Circulation, vol. 81, no. 1, pp. 308 311, 1990.

[87] S. E. Ishikawa and R. W. Schrier, "Pathophysiological roles of arginine vasopressin and aquaporin-2 in impaired water excretion," Clinical Endocrinology, vol. 58, no. 1, pp. 1-17, 2003.

[88] S. Ishikawa, T. Saito, and K. Okada, "Effect of vasopressin antagonist on water excretion in inferior vena cava constriction," Kidney International, vol. 30, no. 1, pp. 49-55, 1986.

[89] M. Naitoh, H. Suzuki, M. Murakami et al., "Effects of oral AVP receptor antagonists OPC-21268 and OPC-31260 on congestive heart failure in conscious dogs," American Journal of Physiology, vol. 267, no. 6, pp. H2245-H2254, 1994.

[90] J. G. Verbalis, "Vasopressin V2 receptor antagonists," Journal of Molecular Endocrinology, vol. 29, no. 1, pp. 1-9, 2002.

[91] D. L. Xu, P. Y. Martin, M. Ohara et al., "Upregulation of aquaporin-2 water channel expression in chronic heart failure rat," Journal of Clinical Investigation, vol. 99, no. 7, pp. 1500-1505, 1997.

[92] J. K. Kim, J. B. Michel, F. Soubrier, J. Durr, P. Corvol, and R. W. Schrier, "Arginine vasopressin gene expression in chronic cardiac failure in rats," Kidney International, vol. 38, no. 5, pp. 818-822, 1990.

[93] P. R. Kalra, S. D. Anker, and A. J. S. Coats, "Water and sodium regulation in chronic heart failure: the role of natriuretic peptides and vasopressin," Cardiovascular Research, vol. 51, no. 3, pp. 495-509, 2001.

[94] M. Gheorghiade, I. Niazi, J. Ouyang et al., "Vasopressin Vreceptor blockade with tolvaptan in patients with chronic heart failure: results from a double-blind, randomized trial," Circulation, vol. 107, no. 21, pp. 2690-2696, 2003.

[95] F. Wong, A. T. Blei, L. M. Blendis, and P. J. Thuluvath, "A vasopressin receptor antagonist (VPA-985) improves serum sodium concentration in patients with hyponatremia: a multicenter, randomized, placebo-controlled trial," Hepatology, vol. 37, no. 1, pp. 182-191, 2003.

[96] C. R. Lee, M. L. Watkins, J. H. Patterson et al., "Vasopressin: a new target for the treatment of heart failure," American Heart Journal, vol. 146, no. 1, pp. 9-18, 2003.

[97] G. De Simone, R. McClelland, J. S. Gottdiener, A. Celentano, R. A. Kronmal, and J. M. Gardin, "Relation of hemodynamics and risk factors to ventricular-vascular interactions in the elderly: the cardiovascular health study," Journal of Hypertension, vol. 19, no. 10, pp. 1893-1903, 2001.

[98] B. H. Lorell, "Transition from hypertrophy to failure," Circulation, vol. 96, no. 11, pp. 3824-3827, 1997.

[99] K. W. Saupe, C. C. Lim, J. S. Ingwall, C. S. Apstein, and F. R. Eberli, "Comparison of hearts with 2 types of pressureoverload left ventricular hypertrophy," Hypertension, vol. 35, no. 5, pp. 1167-1172, 2000.
[100] F. Z. Meerson, M. G. Pshennikova, and I. YU. Malyshev, "Adaptive defense of the organism. Architecture of the structural trace and cross protective effects of adaptation," Annals of the New York Academy of Sciences, vol. 793, pp. 371$385,1996$.

[101] G. T. Schuyler and L. R. Yarbrough, "Changes in myosin and creatine kinase mRNA levels with cardiac hypertrophy and hypothyroidism," Basic Research in Cardiology, vol. 85, no. 5, pp. 481-494, 1990.

[102] H. G. Zimmer, C. Kolbeck-Ruhmkorff, and W. Zierhut, "Cardiac hypertrophy induced by $\alpha$ - and $\beta$-adrenergic receptor stimulation," Cardioscience, vol. 6, no. 1, pp. 47-57, 1995.

[103] D. Greenen, P. Buttrick, and J. Scheuer, "Cardiovascular and hormonal responses to swimming and running in the rat," Journal of Applied Physiology, vol. 65, no. 1, pp. 116-123, 1988.

[104] D. Laurent, P. R. Allegrini, and W. Zierhut, "Different left ventricular remodelling and function in two models of pressure overload as assessed in vivo by magnetic resonance imaging," Journal of Hypertension, vol. 13, no. 6, pp. 693-700, 1995.

[105] K. R. Chien, "Stress pathways and heart failure," Cell, vol. 98, no. 5, pp. 555-558, 1999.

[106] B. Swynghedauw and C. Baillard, "Biology of hypertensive cardiopathy," Current Opinion in Cardiology, vol. 15, no. 4, pp. 247-253, 2000.

[107] M. Bader, "Rat models of cardiovascular diseases," Methods in Molecular Biology, vol. 597, pp. 403-414, 2010.

[108] E. Monnet and J. C. Chachques, "Animal models of heart failure: what is new?" Annals of Thoracic Surgery, vol. 79, no. 4, pp. 1445-1453, 2005.

[109] R. D. Patten and M. R. Hall-Porter, "Small animal models of heart failure: development of novel therapies, past and present," Circulation: Heart Failure, vol. 2, no. 2, pp. 138-144, 2009.

[110] S. F. Flaim, W. J. Minteer, S. H. Nellis, and D. P. Clark, "Chronic arteriovenous shunt: evaluation of a model for heart failure in rat," The American Journal of Physiology, vol. 236, no. 5, pp. H698-H704, 1979.

[111] A. Calderone, N. Takahashi, N. J. Izzo, C. M. Thaik, and W. S. Colucci, "Pressure- and volume-induced left ventricular hypertrophies are associated with distinct myocyte phenotypes and differential induction of peptide growth factor mRNAs," Circulation, vol. 92, no. 9, pp. 2385-2390, 1995.

[112] L. H. Opie, P. J. Commerford, B. J. Gersh, and M. A. Pfeffer, "Controversies in ventricular remodelling," The Lancet, vol. 367, no. 9507, pp. 356-367, 2006.

[113] B. A. Carabello, "Concentric versus eccentric remodeling," Journal of Cardiac Failure, vol. 8, no. 6, pp. S258-S263, 2002.

[114] C. Mihl, W. R. M. Dassen, and H. Kuipers, "Cardiac remodelling: concentric versus eccentric hypertrophy in strength and endurance athletes," Netherlands Heart Journal, vol. 16, no. 4, pp. 129-133, 2008.

[115] B. A. Carabello, "Models of volume overload hypertrophy," Journal of Cardiac Failure, vol. 2, no. 1, pp. 55-64, 1996.

[116] J. N. Cohn, R. Ferrari, and N. Sharpe, "Cardiac remodelingconcepts and clinical implications: a consensus paper from an International Forum on Cardiac Remodeling," Journal of the American College of Cardiology, vol. 35, no. 3, pp. 569$582,2000$.

[117] P. Lijnen and V. Petrov, "Renin-angiotensin system, hypertrophy and gene expression in cardiac myocytes," Journal of Molecular and Cellular Cardiology, vol. 31, no. 5, pp. 949-970, 1999. 
[118] T. Yamazaki and Y. Yazaki, "Molecular basis of cardiac hypertrophy," Zeitschrift fur Kardiologie, vol. 89, no. 1, pp. 16, 2000.

[119] M. Packer, "The neurohormonal hypothesis: a theory to explain the mechanism of disease progression in heart failure," Journal of the American College of Cardiology, vol. 20, no. 1, pp. 248-254, 1992.

[120] A. M. Katz, "Heart failure: a hemodynamic disorder complicated by maladaptive proliferative responses," Journal of Cellular and Molecular Medicine, vol. 7, no. 1, pp. 1-10, 2003.

[121] G. Suzuki, H. Morita, T. Mishima et al., "Effects of longterm monotherapy with eplerenone, a novel aldosterone blocker, on progression of left ventricular dysfunction and remodeling in dogs with heart failure," Circulation, vol. 106, no. 23, pp. 2967-2972, 2002.

[122] J. A. Delyani, E. L. Robinson, and A. E. Rudolph, "Effect of a selective aldosterone receptor antagonist in myocardial infarction," American Journal of Physiology, vol. 281, no. 2, pp. H647-H654, 2001.

[123] A. E. G. Raine, P. Erne, and E. Burgisser, "Atrial natriuretic peptide and atrial pressure in patients with congestive heart failure," New England Journal of Medicine, vol. 315, no. 9, pp. 533-537, 1986.

[124] Y. Shenker, R. S. Sider, E. A. Ostafin, and R. J. Grekin, "Plasma levels of immunoreactive atrial natriuretic factor in healthy subjects and in patients with edema," Journal of Clinical Investigation, vol. 76, no. 4, pp. 1684-1687, 1985.

[125] R. J. Rodeheffer, I. Tanaka, T. Imada, A. S. Hollister, D. Robertson, and T. Inagami, "Atrial pressure and secretion of atrial natriuretic factor into the human central circulation," Journal of the American College of Cardiology, vol. 8, no. 1, pp. 18-26, 1986.

[126] A. S. Maisel, J. Koon, P. Krishnaswamy et al., "Utility of Bnatriuretic peptide as a rapid, point-of-care test for screening patients undergoing echocardiography to determine left ventricular dysfunction," American Heart Journal, vol. 141, no. 3, pp. 367-374, 2001.

[127] H. H. Chen and J. C. Burnett Jr., "The natriuretic peptides in heart failure: diagnostic and therapeutic potentials," Proceedings of the Association of American Physicians, vol. 111, no. 5, pp. 406-416, 1999.

[128] G. M. Bialik, Z. A. Abassi, I. Hammel, J. Winaver, and D. Lewinson, "Evaluation of atrial natriuretic peptide and brain natriuretic peptide in atrial granules of rats with experimental congestive heart failure," Journal of Histochemistry and Cytochemistry, vol. 49, no. 10, pp. 1293-1300, 2001.

[129] G. L. Brower, J. R. Henegar, and J. S. Janicki, “Temporal evaluation of left ventricular remodeling and function in rats with chronic volume overload," American Journal of Physiology, vol. 271, no. 5, pp. H2071-H2078, 1996.

[130] M. Huang, R. L. Hester, and A. C. Guyton, "Hemodynamic changes in rats after opening an arteriovenous fistula," American Journal of Physiology, vol. 262, no. 3, pp. H846H851, 1992.

[131] G. L. Brower and J. S. Janicki, "Contribution of ventricular remodeling to pathogenesis of heart failure in rats," American Journal of Physiology, vol. 280, no. 2, pp. H674-H683, 2001.

[132] X. Wang, B. Ren, S. Liu, E. Sentex, P. S. Tappia, and N. S. Dhalla, "Characterization of cardiac hypertrophy and heart failure due to volume overload in the rat," Journal of Applied Physiology, vol. 94, no. 2, pp. 752-763, 2003.

[133] M. H. Humphreys, H. Al-Bander, J. F. Eneas, and M. Schambelan, "Factors determining electrolyte excretion and renin secretion after closure of an arteriovenous fistula in the dog," Journal of Laboratory and Clinical Medicine, vol. 98, no. 1, pp. 89-98, 1981.

[134] A. Hoffman, J. Winaver, and A. Haramati, "Atrial natriuretic peptide in the recovery from high-output congestive heart failure," American Journal of Medicine, vol. 88, no. 5, p. 547, 1990.

[135] J. J. Alexander and A. L. Imbembo, "Aorta-vena cava fistula," Surgery, vol. 105, no. 1, pp. 1-12, 1989.

[136] I. H. Zucker, A. M. Earle, and J. P. Gilmore, "Changes in the sensitivity of left atrial receptors following reversal of heart failure," The American Journal of Physiology, vol. 237, no. 5, pp. H555-H559, 1979. 


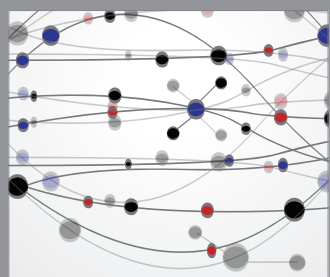

The Scientific World Journal
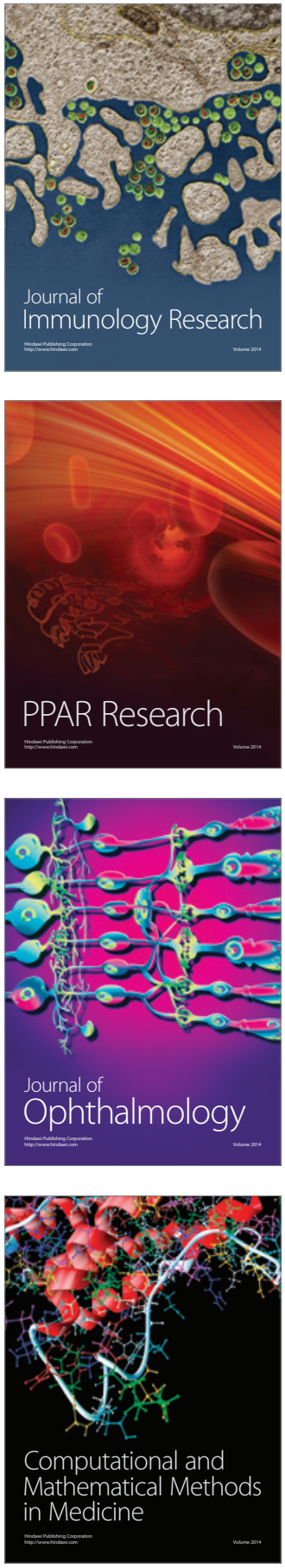

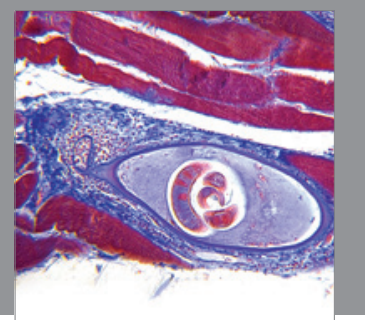

Gastroenterology

Research and Practice
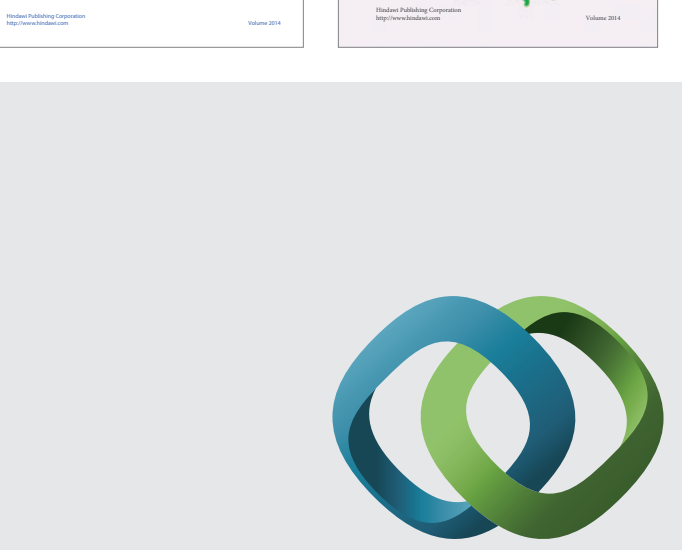

\section{Hindawi}

Submit your manuscripts at

http://www.hindawi.com
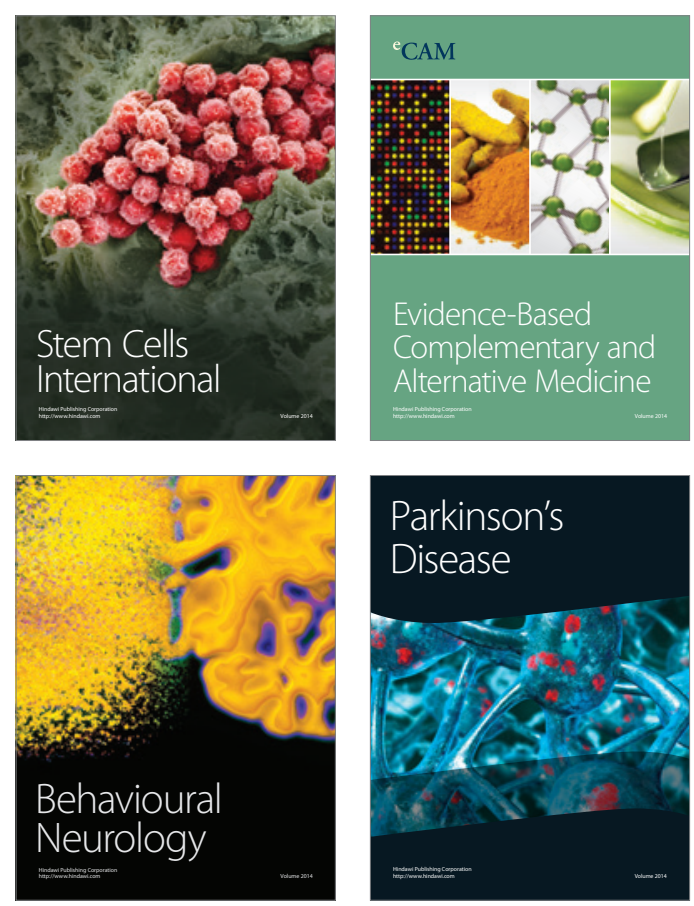

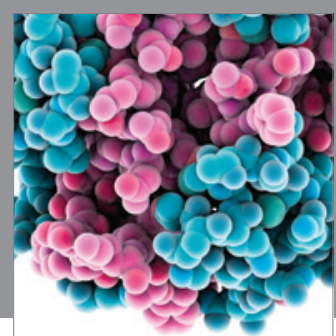

Journal of
Diabetes Research

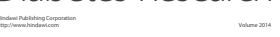

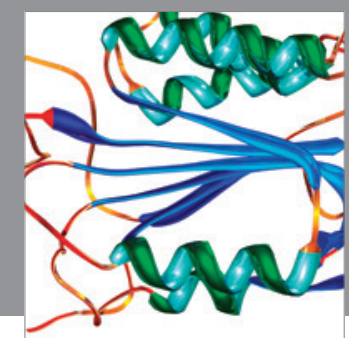

Disease Markers
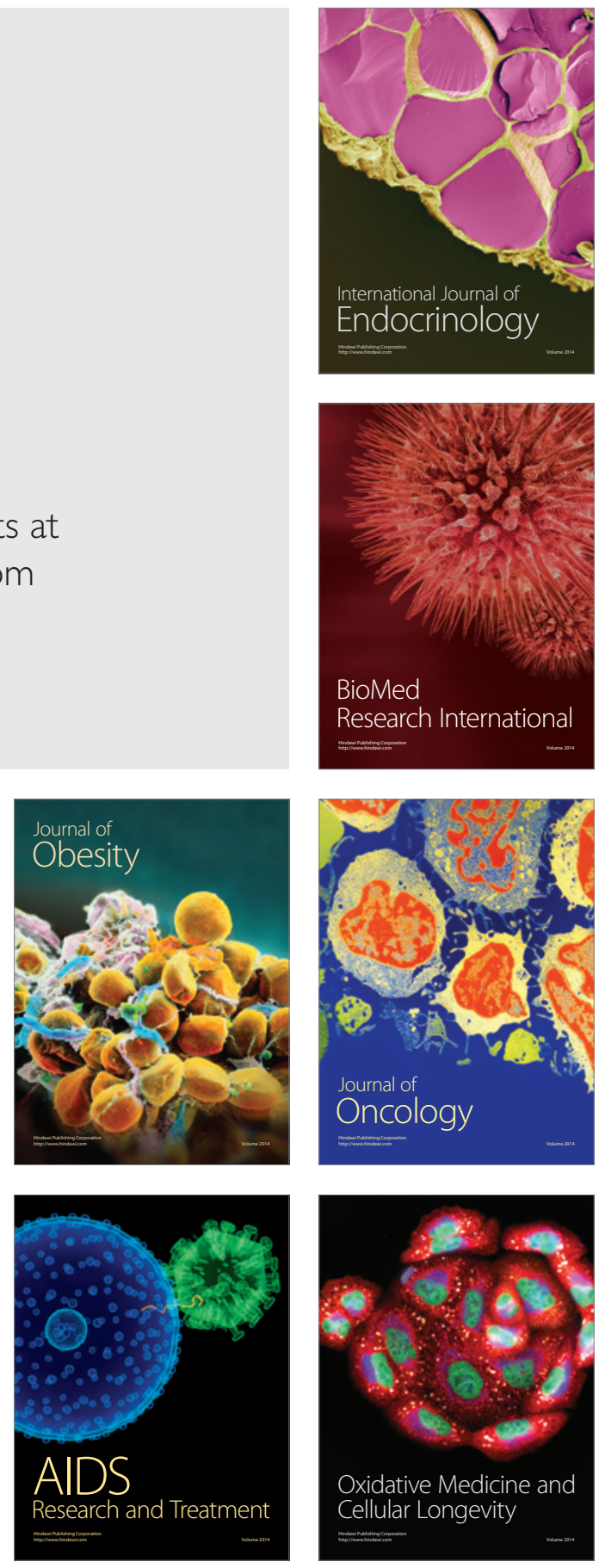